\title{
EFEITO DA SOMATOTROPINA NA HIPERTROFIA DAS FIBRAS MUSCULARES ESQUELÉTICAS E PRECOCIDADE REPRODUTIVA DE NOVILHAS NELORE1
}

PAULO SÉRGIO ANDRADE MOREIRA ${ }^{2}$, ANTONIO CARLOS SILVEIRA ${ }^{3}$, MÁRIO DE BENI ARRIGONI ${ }^{4}$,
CINIRO COSTA ${ }^{4}$, LUIS ARTHUR LOYOLA CHARDULO ${ }^{5}$, LUIZ ROBERTO FURLAN ${ }^{4}$ e VITALINO DAL PAI ${ }^{6}$

RESUMO - O trabalho objetivou avaliar o desempenho produtivo, precocidade sexual e hipertrofia das fibras musculares esqueléticas em resposta à aplicação de somatotropina bovina recombinante (rbST). Foram utilizadas 58 novilhas Nelore de sete meses de idade com peso vivo médio de $193 \mathrm{~kg}$. $\mathrm{O}$ delineamento experimental foi inteiramente casualizado, em um esquema fatorial incompleto e dividido em duas fases experimentais. Na primeira fase, com duração de 150 dias, os animais foram divididos em dois grupos, de acordo com os níveis de rbST, $0 \mathrm{mg}$ (controle) e $500 \mathrm{mg}$, a cada 28 dias. Na Fase II, os animais do grupo controle da Fase I foram divididos em 15 e 14 novilhas, que receberam $0 \mathrm{mg}$ e $500 \mathrm{mg}$ de rbST, respectivamente; os animais tratados com $500 \mathrm{mg}$ na Fase I foram divididos em 15 e 14 novilhas e receberam $500 \mathrm{mg}$ e $1.000 \mathrm{mg}$ de rbST, respectivamente, com intervalos de 28 dias, e dieta em regime de pastejo, durante 180 dias. Foram retirados fragmentos do músculo semitendinosus para análise das fibras, no início e final da Fase I. Os animais foram pesados a cada 28 dias. Os resultados mostraram que não houve diferença significativa $(p>0,05)$ entre os tratamentos quanto ao ganho de peso e quanto à precocidade sexual. Quanto ao diâmetro das fibras, os animais que receberam rbST tiveram um aumento significativo $(\mathrm{p}<0,01)$ tanto nas fibras de contração lenta quanto nas fibras de contração rápida em relação aos animais-controle.

Termos para indexação: hormônios de crescimento animal, reprodução sexual, precocidade, ganho de peso, gado de corte, produção animal.

\section{EFFECT OF SOMATOTROPIN ON HYPERTHROPHY OF SKELETAL MUSCLE FIBERS AND REPRODUCTIVE PRECOCITY OF NELORE HEIFERS}

\begin{abstract}
The objective of this study was to determine the effects of recombinant bovine somatotropin (rbST) on performance, reproductive precocity and hyperthrophy in muscle fibers in Nelore heifers. In the present study, 58 heifers seven months of age weighing $193 \mathrm{~kg}$ were used. The experimental design was completely randomized and divided in two phases. In the first phase of 150 days, the levels of rbSt were $0 \mathrm{mg}$ and $500 \mathrm{mg}$ at 28 day intervals. In the phase II, each group of phase I was divided in two new groups and the levels of rbST were $0 \mathrm{mg}$ and $500 \mathrm{mg}$ for the control group, and $500 \mathrm{mg}$ and 1,000 mg for $500 \mathrm{mg}$ group of phase I, at 28 day intervals. Diet was exclusively pasture by 180 days. Biopsy of semitendinosus muscle was done for analysis of fibers at the beginning and at the end of phase I. The animals were weighed monthly (28 days). Results showed no significative differences ( $>>0.05$ ) among treatments for gain of weight and for sexual precocity. For $\mathrm{SO}$ (slow oxidative), FOG (fast oxidative glycolitic) and FG (fast glycolitic) muscle fiber diameter a significative difference $(\mathrm{p}<0.01)$ with higher values for rbST treated heifers was observed.
\end{abstract}

Index terms: animal growth hormones, sexual reproduction, precocity, weight gain, beef cattle, animal production.

\footnotetext{
${ }^{1}$ Aceito para publicação em 20 de dezembro de 2000. Extraído da dissertação de mestrado apresentada pelo primeiro autor à Faculdade de Medicina Veterinária e Zootecnia (FMVZ), Universidade Estadual Paulista (UNESP), Botucatu, SP.

${ }^{2}$ Méd. Vet., M.Sc., Dep. de Morfologia e Histologia, Instituto de Biociências (IB), UNESP, Caixa Postal 560, CEP 18618-000 Botucatu, SP. E-mail: secdmna@fca.unesp.br
}

\footnotetext{
${ }^{3}$ Eng. Agrôn., Prof. Titular, Dep. de Melhoramento Nutrição Animal (DMNA), FMVZ, UNESP. E-mail: secdmna@fca.unesp.br

${ }^{4}$ Zoot., Dr., Prof. Assistente, DMNA, FMVZ, UNESP E-mail: arrigoni@fca.unesp.br, secdmna@fca.unesp.br

${ }^{5}$ Zoot., M.Sc., Prof. Assistente, DMNA, FMVZ, UNESP. E-mail: lchard@fcav.unesp.br

${ }^{6}$ Biól., Prof. Titular, Dep. de Morfologia e Histologia, IB, UNESP. E-mail: morfologia@ibb.unesp.br
} 


\section{INTRODUÇÃO}

A precocidade sexual não tem sido priorizada no processo de seleção a que têm sido submetidos os zebuínos no Brasil, o que é evidenciado pela reprodução tardia destes animais; o primeiro parto dificilmente ocorria antes dos 24 meses de idade, o que concorria para um baixo desfrute do rebanho.

Uma alternativa acessível seria a manipulação de fatores que alterassem e antecipassem a precocidade das fêmeas, como as que foram associadas à herança genética e aos fatores ambientais. Entretanto, somente as técnicas de seleção e cruzamentos não foram capazes de solucionar muitas das limitações da produção animal, pois geralmente demandam muito tempo para produzir os primeiros resultados. Assim, associando-se o potencial genético dos produtos de cruzamento com a manipulação de fatores ambientais pode ser uma boa alternativa para conseguir a melhora dos índices zootécnicos.

Neste sentido, vários estudos foram conduzidos sobre a manipulação dos fatores genéticos e ambientais de crescimento. Dentre os fatores ambientais, alterar a dieta durante as fases de crescimento (Ryan, 1990) foi um dos pontos básicos, uma vez que o plano nutricional pode alterar o início da puberdade. A condição nutricional e a taxa de crescimento também podem afetar o início da puberdade em novilhas (Stanko et al., 1994). Na expressão desses sinais da puberdade não se pode ignorar o papel central do hormônio de crescimento $(\mathrm{GH})$ ou somatotropina bovina recombinante ( $\mathrm{rbST}$ ), na caracterização das diferentes fases de crescimento. Neste sentido, Hall et al. (1994) determinaram que o tratamento contínuo com rbST em novilhas pré-púberes provocou alterações no metabolismo intermediário e promoveu o aumento no crescimento ósseo e muscular, porém não houve alteração quanto ao início da puberdade.

O GH está associado ao crescimento de diversos tecidos; e entre estes, encontram-se os tecidos reprodutivos. O GH encontra-se também associado com o estímulo da atividade ovariana. Ambos, GH e insulina (IGF-1), são conhecidos estimulantes das funções celulares da granulosa e da teca, mas as relações de interdependência entre GH e IGF-1 dificultam o compreendimento dos mecanismos de con- trole destes hormônios sobre as funções reprodutivas dos animais. Uma vez que não são encontrados receptores de IGF-1 nos folículos, acredita-se que os efeitos mediados por este hormônio sejam regulados pelos receptores de insulina. Acredita-se que os efeitos do GH na função ovariana in vivo possam ser resultantes de mecanismos indiretos de resistência à insulina, induzido e mediado pelo GH. O mesmo autor, em experimento realizado com ovelhas, observou que a suplementação de GH por período curto não alterou as funções foliculares dos animais e sua atividade reprodutiva (Scaramuzzi, 1998).

Por outro lado, a ação do hormônio de crescimento através de fatores de crescimento semelhantes à insulina (IGF-1) tem estimulado o estudo de sua ação bioquímica e fisiológica. $\mathrm{O}$ efeito estimulador de IGF-1 na produção de progesterona foi constatado em ruminantes por Savion et al. (1981) e Langhout et al. (1991). Spicer \& Enright (1991) demonstraram que concentrações de IGF-1 nos bovinos aumentaram com o incremento do tratamento folicular.

Em estudos mais recentes, algumas relações diretas entre GH e IGF-1 nas funções reprodutivas de fêmeas foram relatadas, por Spicer et al. (1993), que demonstraram in vitro que o IGF-1 foi capaz de estimular a proliferação das células da granulosa bovina, e que o FSH e o IGF-1 estimularam a produção de estradiol e progesterona. Estes estudos indicaram que o IGF-1 pode ter efeito direto e local nas funções ovariano-foliculares em bovinos, e que estes efeitos são influenciados pelos diferentes estágios de maturação do folículo. Stanko et al. (1994) observaram que fêmeas de 15 meses de idade e com deficiência de Fator de Liberação do Hormônio de Crescimento (GRF) e submetidas a reposição diária com rbST não apresentaram atividades ovarianas e foliculares mesmo após o tratamento, enquanto todas as fêmeas com 18 meses, ao final do período experimental, apresentaram cio, tendo ou não recebido rbST.

Lucy et al. (1994), trabalhando com novilhas da raça Holandesa tratadas com rbST, concluíram que a aplicação do hormônio incrementou o desenvolvimento inicial do corpo lúteo, como antecipou a segunda onda folicular, demonstrando, dessa maneira, o papel do rbST ou IGF-1 como moderadores da dinâmica folicular ovariana em novilhas. 
Em bovinos, também fica evidente o fato de que hormônios esteróides (androgênios e testosterona) agem estimulando a liberação de GH (Gopinath \& Kitts, 1984). Enright et al. (1993), estudando fêmeas jovens mestiças Hereford $\mathrm{x}$ Friesan ovariectomizadas, concluíram que os ovários representaram função importante na modulação do efeito da dieta pelo eixo GH/IGF-1. Deste modo, comprova-se que, além da ação da somatotropina como fator de crescimento, há também outra ação deste hormônio sobre as funções reprodutivas primárias de novilhas de corte.

O crescimento muscular também está associado ao aumento do diâmetro das fibras, e, segundo Johnston et al. (1975), o diâmetro das fibras foi influenciado pelo nível nutricional da dieta. Owens et al. (1993) relataram que, quando o nível nutricional da dieta não atende à exigência de crescimento, ou seja, restrição alimentar discreta, durante determinado período de tempo após um retorno à alimentação que atende às exigências do animal, há um ganho denominado ganho compensatório, em que ocorre uma alteração na composição e no diâmetro das fibras, promovendo uma rápida hipertrofia muscular.

Este trabalho teve como objetivo avaliar o desempenho produtivo, a precocidade sexual, e a hipertrofia das fibras musculares esqueléticas, em resposta à aplicação de somatotropina bovina recombinante (rbST) em novilhas Nelore.

\section{MATERIAL E MÉTODOS}

O experimento foi conduzido na Fazenda Morro Grande, de propriedade da Nomurabrás-Instituto de Desenvolvimento Agropecuário, Ltda., localizada no município de Perdizes, MG.

Foram utilizadas 58 novilhas Nelore, identificadas individualmente, com idade média de sete meses e peso médio inicial de $193 \mathrm{~kg}$.

No inicio da fase experimental, os animais foram desverminados, com repetição posterior a cada quatro meses. Foram também realizadas vacinações recomendadas de acordo com o calendário estabelecido pelos órgãos governamentais da região.

O presente estudo foi dividido em duas fases experimentais, sendo a primeira, denominada de Fase I, que teve duração de, aproximadamente, 150 dias (julho a novembro de 1996), e a segunda, denominada Fase II, com duração de 180 dias aproximadamente (novembro de 1996 à maio de 1997).
$\mathrm{Na}$ Fase I os animais foram distribuídos em dois tratamentos: 29 animais, sem aplicação de $\mathrm{rbST}(0 \mathrm{mg})$ submetidos a solução salina a cada 28 dias e 29 animais, com aplicação de $500 \mathrm{mg}$ de rbSt a cada 28 dias.

$\mathrm{Na}$ Fase II, o grupo sem tratamento com rbST $(0 \mathrm{mg})$ da Fase I foi dividido em 15 e 14 animais que foram tratados com $0 \mathrm{mg}$ e $500 \mathrm{mg}$ de rbST, respectivamente, a cada 28 dias; o grupo da Fase I tratado com $500 \mathrm{mg}$ de rbST foi dividido em 15 e 14 novilhas que receberam $500 \mathrm{mg}$ (a cada 28 dias) e $1.000 \mathrm{mg}$ (a cada 14 dias) de rbST, respectivamente. Para homogeneizar o manejo, com exceção do tratamento de $1.000 \mathrm{mg}$, os animais receberam solução salina em todos os tratamentos a cada 14 dias.

Durante todo o período experimental, os animais permaneceram em dois piquetes de Braquiaria brizantha, cv. Marandu, semelhante em formação e manejo, delimitados por cerca de arame liso, com, aproximadamente, 50 ha cada. Os piquetes foram pastejados em sistema alternado, de acordo com a melhor disponibilidade de massa verde. Cada piquete possuía um bebedouro, um cocho coberto para mistura múltipla, composta basicamente por $65 \%$ de cama de frango e $35 \%$ de milho moído com consumo de, aproximadamente, $3 \mathrm{~kg} / \mathrm{animal} / \mathrm{dia}$, durante a Fase I. Na Fase II, os animais permaneceram com uma dieta exclusiva de pastagem e suplementação mineral.

A aplicação do rbST (LACTOTROPIN-500 mg - Elanco) foi realizada por meio de injeções subcutâneas na região do músculo coccígeo na base da cauda, de acordo com as dosagens e intervalos demonstrados na Tabela 1.Todos os animais foram pesados no início do experimento, e, posteriormente, com intervalo de 28 dias, até o final da Fase II, coincidindo com a aplicação de rbST ou solução salina.

A coleta de amostras de tecido muscular ocorreu no inicio e no final da Fase I, nos meses de julho e novembro, respectivamente. A retirada das amostras foi feita por meio da técnica de biopsia cirúrgica do músculo semitendinosus. Para tal intervenção, foi realizada uma lavagem local com água e sabão, tricotomia e desinfecção local com álcool iodado. Realizou-se uma pequena incisão com bisturi no local, para posterior retirada do fragmento, conforme técnica descrita por Dubowitz (1972).

Imediatamente após a retirada dos fragmentos musculares, estes foram congelados em $\mathrm{N}$-hexana, previamente resfriados em nitrogênio líquido, segundo a metodologia de Chayen (1969), durante 2 minutos. Posteriormente, foram acondicionados em pequenos tubos, identificados e armazenados em botijões de nitrogênio líquido.

$\mathrm{Na}$ avaliação da morfologia e das características dos tipos de fibras musculares, utilizou-se o Laboratório de Histoenzimologia do Departamento de Morfologia do Ins- 
tituto de Biociência, UNESP, Botucatu. Os fragmentos foram retirados dos botijões de Nitrogênio líquido e colocados na câmara do micrótomo criostático Keichert Jung modelo CM 1.800 a $-20^{\circ} \mathrm{C}$, e assim mantidos por uma hora, de acordo com Pullen (1977). No processamento do material, os blocos foram fixados aos suportes metálicos do criostato, utilizando-se, para isso, o adesivo líquido OCT Tissue TEK. Nesta etapa, os fragmentos foram orientados para obtenção de cortes transversais das fibras. A seguir, foram obtidas várias séries de cortes, com $10 \mu \mathrm{m}$ de espessura, as quais foram submetidas às técnicas descritas a seguir.

No estudo das características metabólicas das fibras musculares, várias séries de cortes foram submetidas à reação Nicotinamida Adenina Dinucleotídeo Tetrazólio Redutase (NADH-TR), segundo Peter et al. (1972). Para habilidade contrátil das fibras, a reação ATPase miofibrilar (m-ATPase), após pré-incubação em meio alcalino ( $\mathrm{pH} 10,4$ ) e em meio ácido ( $\mathrm{pH} 4,6$ ), conforme Dubowitz $\&$ Brooke (1984). As fibras musculares foram então classificadas em SO (slow oxidative), fibras de contração lenta e metabolismo oxidativo, FOG (fast oxidative glycolitic), fibras de contração rápida e metabolismo oxidativoglicolítico, e FG (fast glycolitic), fibras de contração rápida e metabolismo glicolítico.

$\mathrm{Na}$ avaliação do grau de hipertrofia das fibras, foi mensurado o menor diâmetro das fibras musculares (Dubowitz, 1972). Nesta etapa utilizou-se um sistema de Análise de Imagens Computadorizada (OPTIMAS, 4.10), em que foram mensuradas 200 fibras, sendo 100 de contração rápida (FG e FOG) e 100 de contração lenta (SO).

Para avaliação do desempenho reprodutivo, após o término da Fase II (junho a janeiro de 1998), foi interrompida a aplicação do hormônio, e as fêmeas permaneceram com dois rufiões. As observações dos sinais relacionados ao cio foram feitas pela manhã e à tarde. A detecção baseou-se na percepção visual feita pelo tratador, com o auxílio de um buçal marcador.

As fêmeas que apresentavam sinais de cio pela manhã eram inseminadas à tarde, e as fêmeas que entraram no cio à tarde eram inseminadas no dia seguinte pela manhã. Para a realização do processo, as fêmeas eram conduzidas a um brete de contenção, onde era feita uma limpeza externa da região vulvar com água e sabão, e então realizada a inseminação conforme método descrito por Mies Filho (1970). Para diagnóstico de gestação, foi feita palpação transretal, 40 dias após a data da inseminação.

$\mathrm{O}$ delineamento experimental adotado foi inteiramente casualizado, conforme modelo a seguir:

$\mathrm{Y}_{\mathrm{ijk}}=\mathrm{u}+\mathrm{Ti}+\mathrm{Mj}+(\mathrm{TM}) \mathrm{ij}+\mathrm{E} \mathrm{ijk}$, onde

$\mathrm{Y}_{\mathrm{ijk}}=$ variável dependente;

Pesq. agropec. bras., Brasília, v.35, n.9, p.1853-1860, set. 2000 $\mathrm{u}=$ média geral;

$\mathrm{Ti}=$ efeito do $\mathrm{i}_{\text {ésimo }}$ tratamento para $\mathrm{i}=1,2,3,4$;

$\mathrm{Mj}=$ efeito do jésimo momento para $\mathrm{j}=1-13$;

(TM) $\mathrm{ij}$ = efeito da interação entre iésimo tratamento com

o jésimo momento;

Eijk $=$ erro experimental.

Para análise estatística dos valores de peso vivo dos animais, utilizou-se a análise de perfil (Morrison, 1967), que leva em consideração a estrutura de dependência das medidas efetuadas ao longo do tempo no mesmo conjunto de animais, com o propósito de obter uma análise mais precisa (Guidoni, 1994).

A avaliação dos dados referentes às fibras musculares e ao desempenho reprodutivo foi feita segundo o procedimento GLM (SAS Institute, 1982). Nas hipóteses testadas, as estatísticas calculadas ( $\mathrm{F}$ e t) foram consideradas significativas quando $\mathrm{p}<0,05$, em que $\mathrm{p}$ é o nível de significância associado à estatística, calculado, e as médias foram comparadas pelo teste de Tukey.

\section{RESULTADOS E DISCUSSÃO}

Na Tabela 1 são apresentados os valores médios obtidos quanto ao peso vivo dos animais. Observase que esses valores estão de acordo com Silveira (1995), com relação à média do desmame da fêmeas zebuínas nas regiões de cerrados do Brasil central, com o peso vivo inicial médio de 193,2 kg, com idade média de sete a oito meses. Isto vem demonstrar que, além da uniformidade apresentada pelo lote experimental, os animais tiveram bom desenvolvimento durante a fase de cria.

A análise estatística dos resultados demonstrou que os valores de peso vivo apresentados pelos animais de cada tratamento foram semelhantes $(p>0,05)$, ao longo do tempo, demonstrando, que a utilização de rbST não afetou o desenvolvimento dos animais (Tabela 1). Stanko et al. (1994) também não obtiveram variações estatisticamente significativas entre os tratamentos testados. Contrariando esses resultados, Dalke et al. ( 1992) e Moseley et al. (1992) obtiveram um aumento no ganho de peso diário de $10 \%$ nos animais que receberam rbST, em relação aos animais-controle. Early et al. (1990) encontraram um ganho de peso de $15 \%$ maior em relação aos animais tratados com rbST; esta taxa foi de $49 \%$ entre a segunda e quarta semana do experimento. Os dois grupos de autores citados trabalharam com animais em confinamento, com dietas de terminação; portanto, 
pode-se admitir a existência de uma interação entre o nível nutricional da dieta e a suplementação de rbST.

A Tabela 1 mostra que não houve aumento de peso vivo dos animais do início ao final da Fase I, o que demonstra que a suplementação energética e protéica oferecida no período de seca invernal foi insuficiente, fato este, evidenciado pela perda de peso $(6,3 \mathrm{~kg})$, no período compreendido entre os meses de julho a novembro.

No período de dezembro de 1996 a maio de 1997, quando os animais permaneceram em dieta exclusiva de pastagem, houve um aumento significativo $(\mathrm{p}<0,01)$ no peso vivo médio dos animais em todos os tratamentos $(287,0 \pm 27,5 \mathrm{~kg})$, correspondendo a um ganho médio diário de $0,596 \mathrm{~kg} / \mathrm{animal}$, demonstrando, assim, que as condições de pastagem foram adequadas para o seu desenvolvimento.

Ficou evidente uma diminuição média de 3,19\% no peso vivo durante a Fase I, seca invernal, seguido de ganho, correspondendo a, aproximadamente, $50 \%$ em relação ao peso ao desmame, considerando o peso do início do experimento.

O uso de somatotropina bovina recombinante com o propósito de promover maior precocidade reprodutiva em novilhas Nelore não apresentou efeito significativo ( $p>0,05)$, entre os tratamentos testados; esses animais foram apresentar evidências de atividade reprodutiva somente 6 meses após serem interrompidas as suplementações de rbST. Estes dados concordam com os resultados obtidos por Stanko et al. (1994), que, trabalhando com fêmeas pré- púberes, não encontraram diferença entre os tratamentos.

Os resultados encontrados confirmam a interdependência entre o nível nutricional da dieta com as características de crescimento e precocidade sexual. Como pode-se visualizar na Tabela 2, não houve diferença significativa quanto à incidência de cios durante o período observado, bem como a antecipação do ciclo estral, pois as fêmeas apresentaram sinais de estro aos 29 meses de idade. Possivelmente, a suplementação alimentar não foi suficiente para alterar o status nutricional das novilhas para que houvesse uma resposta benéfica associada à aplicação do rbST, pois a ação do $\mathrm{GH}$ nos aspectos reprodutivos pode estar interligadas com os receptores de IGF-1, e portanto, a condição corporal das novilhas poderia estar relacionada com baixos níveis de insulina, não permitindo o efeito associativo do rbST no parâmetro reprodutivo.

O crescimento animal é conseqüência da atividade de síntese dos tecidos (Owens et al., 1993). Neste sentido, o grau de hipertrofia das fibras musculares esqueléticas pode ser utilizado como parâmetro para se medir a taxa de crescimento dos animais. Os animais que receberam rbST apresentaram um aumento significativo $(\mathrm{p}<0,01)$ no diâmetro médio das fibras de contração rápida (FG e FOG) e das fibras de contração lenta (SO) (Tabela 3). Resultados semelhantes foram encontrados por Johnston et al. (1975), que, trabalhando com bovinos tratados com rbST, determinaram um aumento no diâmetro médio das fibras, especialmente nas fibras vermelhas. $\mathrm{O}$ aumento mé-

TABELA 1. Média e desvio-padrão da variação de peso vivo (PV) inicial e final de novilhas Nelore, submetidas à aplicação de somatotropina bovina recombinante (rbST) em duas fases.

\begin{tabular}{|c|c|c|c|c|c|}
\hline \multirow{2}{*}{\multicolumn{2}{|c|}{$\begin{array}{c}\text { Tratamento com rbST } \\
\text { (mg/animal) }\end{array}$}} & \multirow{3}{*}{$\begin{array}{l}\mathrm{N}^{\mathrm{o}} \text { de } \\
\text { animais }\end{array}$} & \multirow{3}{*}{$\begin{array}{l}\text { PV inicial } \\
\quad(\mathrm{kg})\end{array}$} & \multicolumn{2}{|c|}{ PV final (kg) } \\
\hline & & & & \multirow[t]{2}{*}{ Fase 1} & \multirow[t]{2}{*}{ Fase 2} \\
\hline Fase I & Fase II & & & & \\
\hline 0 & 0 & 15 & $189,8 \pm 18,7$ & $183,5 \pm 17,1$ & $283,5 \pm 29,5$ \\
\hline 0 & 500 & 14 & $197,0 \pm 20,9$ & $188,3 \pm 18,4$ & $284,4 \pm 27,4$ \\
\hline 500 & 500 & 15 & $196,1 \pm 22,9$ & $189,9 \pm 22,6$ & $285,2 \pm 27,9$ \\
\hline 500 & 1000 & 14 & $190,0 \pm 15,4$ & $185,9 \pm 15,1$ & $294,7 \pm 25,4$ \\
\hline Média & & & $193,2 \pm 9,4$ & $186,9 \pm 18,3$ & $287,0 \pm 27,5$ \\
\hline
\end{tabular}


dio do diâmetro das fibras variou significativamente $(p<0,01)$ entre os tipos de fibras. As fibras de contração rápida tiveram um aumento de $54 \%$ em seu diâmetro enquanto que, nas fibras de contração lenta, o aumento foi de $77 \%$ em relação ao seu diâmetro inicial, em que o diâmetro médio das fibras lenta foi sempre menor, independentemente do tratamento. Contrariamente às observações de Trenkle et al. (1978), que relataram aumento no diâmetro médio das fibras, associado ao aumento do peso vivo, o presente estudo evidenciou queda de peso vivo médio dos animais. Tal fato pode ser explicado pela ativi- dade lipolítica e diabetogênica do GH (Gluckman et al., 1987) permitindo que haja uma maior mobilização da gordura para síntese de proteína nos animais que receberam rbST. Contudo, os animais que não receberam hormônio também apresentaram aumento no diâmetro da fibra, como provável resposta ao crescimento fisiológico do animal, o que demonstra que o aumento do peso vivo nem sempre corresponde à taxa de crescimento do animal. Além disso, como relatado por Dalke et al. (1992), o aumento de peso quando da aplicação ou tratamento com rbST pode estar associado ao aumento de peso

TABELA 2. Valores médios do aparecimento de cio e idade média de novilhas Nelore, durante a fase de monta.

\begin{tabular}{|c|c|c|c|c|c|}
\hline \multirow[t]{2}{*}{ Tratamento } & \multicolumn{2}{|c|}{ Fase I } & \multicolumn{2}{|c|}{ Fase II } & \multirow[t]{2}{*}{ Média } \\
\hline & $0 \mathrm{mg}$ & $500 \mathrm{mg}$ & $500 \mathrm{mg}$ & $1.000 \mathrm{mg}$ & \\
\hline $\mathrm{N}^{\mathrm{o}}$ total de animais & 15 & 14 & 15 & 14 & \\
\hline $\mathrm{N}^{\mathrm{o}}$ de animais que apresentaram cio & 6 & 7 & 5 & 8 & \\
\hline $\begin{array}{l}\text { Idade média dos animais que } \\
\text { apresentaram cio ( meses) }\end{array}$ & 29 & 29 & 29 & 29 & \\
\hline Porcentagem & 40,00 & 50,00 & 33,33 & 57,14 & 44,83 \\
\hline
\end{tabular}

TABELA 3. Diâmetro médio ( $\mu \mathrm{m})$ das fibras musculares de contração rápida e lenta, em 6 novilhas Nelore tratadas com somatotropina bovina recombinante (rbST) e não tratadas (controle), no início e final da fase $I^{1}$.

\begin{tabular}{|c|c|c|c|c|c|c|}
\hline \multirow[t]{2}{*}{ Animal } & \multicolumn{3}{|c|}{ Rápida } & \multicolumn{3}{|c|}{ Lenta } \\
\hline & Início & Final & Diferença & Início & Final & Diferença \\
\hline & \multicolumn{6}{|c|}{ Controle } \\
\hline 1 & 29,12 & 36,49 & & 25,08 & 25,69 & \\
\hline 2 & 32,80 & 34,95 & & 26,19 & 26,51 & \\
\hline 3 & 35,20 & 39,35 & & 25,32 & 25,86 & \\
\hline 4 & 30,65 & 39,95 & & 24,04 & 25,37 & \\
\hline 5 & 39,90 & 53,34 & & 24,96 & 29,27 & \\
\hline 6 & 32,25 & 34,90 & & 26,02 & 26,52 & \\
\hline Média & 33,32 & 39,83 & $6,51 *$ & 25,26 & 28,87 & $3,61 *$ \\
\hline \multicolumn{7}{|c|}{ rbST } \\
\hline 1 & 28,99 & 45,32 & & 25,79 & 36,32 & \\
\hline 2 & 36,37 & 49,94 & & 26,67 & 34,13 & \\
\hline 3 & 32,10 & 35,90 & & 23,59 & 28,21 & \\
\hline 4 & 33,45 & 37,18 & & 27,97 & 27,67 & \\
\hline 5 & 21,18 & 37,53 & & 19,60 & 27,49 & \\
\hline 6 & 22,57 & 29,04 & & 19,90 & 28,09 & \\
\hline Média & 29,11 & 39,15 & $10,04 *$ & 23,92 & 30,31 & $6,39 *$ \\
\hline
\end{tabular}

* Significativo a $1 \%$ de probabilidade.

${ }^{1} \mathrm{Na}$ fase I, 29 animais não receberam o tratamento com rbST (controle) e 29 animais foram tratados com $500 \mathrm{mg}$ de rbST. 
dos tecidos viscerais, ou seja, dos componentes não-carcaça.

\section{CONCLUSÃO}

A aplicação ou tratamento-suplementação com rbST aumenta a hipertrofia das fibras musculares em razão da idade, sem melhorar o ganho de peso ou a precocidade reprodutiva de novilhas Nelore.

\section{REFERÊNCIAS}

CHAYEN, J. A guide to practical histochemistry. London : O. Boyd, 1969. p.261-269,

DALKE, B.S.; ROEDER, R.A.; KASSER, T.R.; VEENHUIZEN, J.J.; HUNT, C.W.; HINMAN, D.D.; SCHELLING, G.T. Dose-response effects of recombinant bovine somatotropin implants on feedlot performance in steers. Journal of Animal Science, Champaign, v.70, p.2130-2137, 1992.

DUBOWITZ, V. Muscle biopsy: a practical approach. 2.ed. London : Bailliere Tindall, 1972. p.235-270.

DUBOWITZ, V.; BROOKE, M. Muscle biopsy. London :W. B. Saunders, 1984. p.472-485.

EARLY, R.J.; McBRIDE, B.W.; BALL, R.O. Growth and metabolism in somatotropin-treated steers. I. Growth, serum chemistry and carcass weights. Journal of Animal Science, Champaign, v.68, p.4134-4143, 1990.

ENRIGHT, W.J.; PRENDIVILLE, D.J.; SPICER, L.J.; STRICKER, P.R.; MOLLONEY, A.P.; MOWLES, T.F.; CAMPBELL, R.M. Effects of growth hormone releasing hormone on growth, feed efficiency, carcass characteristics and blood hormones and metabolites in beef heifers. Journal of Animal Science, Champaign, v.71, p.2395-2405, 1993.

GLUCKMAN, P.D.; BREIER, B.H.; DAVIS, S.R Physiology of somatotropic axis with particular reference to the ruminant. Journal of Dairy Science, Champaign, v.70, p.442-466, 1987.

GOPINATH, R.; KITTS, W.O. Growth hormone secretion and clearance rats in growing beef steers implanted with estrogenic anabolic compounds. Growth, Bar Harbor, v.48, p.499-509, 1984.

GUIDONI, A.L. Alternativas para comparar tratamentos envolvendo o desempenho nutricional animal.
Piracicaba : ESALQ, 1994. 105p. Tese de Doutorado.

HALL, J.B.; SCHILLO, K.K.; FITZGERALD, B.P.; BRADLEY, N.W. Effects of recombinant bovine somatotropin and dietary energy intake on growth, secretion of luteining hormone, follicular development and onset of puberty in beef heifers. Journal of Animal Science, Champaign, v.72, p.709718, 1994.

JOHNSTON, M.D.; STWART, D.F.; MOODY, W.G.; BOLLING, J.A.; KEMP, J.D. Effect and time of feed on size and distribution of breed muscle fiber types. Journal of Animal Science, Champaign, v.40, p.613$620,1975$.

LANGHOUT, D.J.; SPICER, L.J.; GEISERT, R.D. Development of a culture system for bovine granulosa cells: effects of growth hormone estradiol and gonadotropin on cell proliferation, steroid genesis and protein synthesis. Journal of Animal Science, Champaign, v.69, p.3321-3334, 1991.

LUCY, M.C.; CURRAN, T.L.; COLLIER, R.J.; CODE, W.J. Extend function of the corpus luteum and earlier development of the second folicular wave in heifers treated with bovine somatotropin. Theriogenology, New York, v.41, p.561-572, 1994.

MIES FILHO, A. Reprodução dos animais e inseminação artificial. Porto Alegre : Sulina, 1970. p.442-457.

MORRISON, F.B. Multivariate statistical methods. New York : McGraw-Hill, 1967. 338p.

MOSELEY, W.M.; PAULISSEN, J.B.; GOODWIN, M.C.; ALANIZ, G.R.; CLAFLIN, W.H. Recombinant bovine somatotropin improves growth performance in finishing beef steers. Journal of Animal Science, Champaign, v.70, p.412-425, 1992.

OWENS, F.N.; DUBESKI, P.; HANSON, C.F. Factors that alter the growth and development of ruminant. Journal of Animal Science, Champaign, v.71, p.3138-3150, 1993.

PETER, J.B.; BARNARD, R.J.; EDGERTON, U.R.; GILLESPIE, C.A.; STEMPLE, K.E. Metabolic profiles of three types of fibers of skeletal muscles in guinea pig and rabbits. Biochemistry, Washington, v.11, p.2627-2636, 1972.

PULLEN, A.H. The distribution and relative size of fiber types in the extensor digitorun longus and soleus muscle of the adult rat. Journal of Anatomy, Cambridge, Grã-Bretanha, v.123, p.467-486, 1977.

Pesq. agropec. bras., Brasília, v.35, n.9, p.1853-1860, set. 2000 
RYAN, W.J. Compensatory growth in cattle an sheep. Nutrition Abstracts and Reviews, Series B, Wallingford, v.60, p.9, 1990.

SAS INSTITUTE (Cary, Estados Unidos). SAS user's guide: statistics. Cary, 1982. 860p.

SAVION, N.; LUI, G.; LAHERTY, R.; GOSPODAROWICZ, D. Factors controlling proliferation and progesterone production by bovine granulosa cells in serum-free medium. Endocrinology, Baltimore, v.109, p.409-415, 1981.

SILVEIRA, A.C. Sistema de produção do novilho precoce. In: ENCONTRO NACIONAL SOBRE PRODUÇÃO DO NOVILHO PRECOCE, 1995, Campinas. Anais. Campinas : CATI, 1995. p.53-77.

SCARAMUZZI, R.J. The effect of growth hormone on the secretion of follicular steroids and ovulation rate in the sheep. Biotechnologie, Agronomie, Societe et Environnement, Gembloux, v.2, p.57-64, 1998. Special issue.

SPICER, L.J.; ENRIGHT, W.J. Concentrations of insulinlike growth factor-I and steroids in follicular fluid of preovulatory bovine ovarian follicles: effect of daily infections of a growth hormone-releasing factor analogy and tryotropin-releasing hormone. Journal of Animal Science, Champaign, v.69, p.1133-1144, 1991.

SPICER, L.J.; ALPIZAR, E.; ECHTERNKAMP, S.E. Effects of insulin, insulin-like growth factor-I, and gonadotropins on bovine granulosa cell proliferation, progesterone production, estradiol production, and insulin-like factor-I production in vitro. Journal of Animal Science, Champaign, v.71, p.1232-1241, 1993.

STANKO, L.R.; ARMSTRONG, J.D.; COHICK, W.S.; HARVEY, R.W.; SIMPSON, R.B.; HARTNELL, G.F.; HEIMER, E.P.; CAMPBELL, R.M. Effects of daily replacement therapy with recombinant bovine somatotropin on somatotropin, insulin-like growth factor I, and onset of puberty in beef heifers immunized against growth hormone-releasing factor. Journal of Animal Science, Champaign,v.72, p.1786-1795, 1994.

TRENKLE, A.; DE WITT, D.L.; TOPEL, D.G. Influence of age, nutrition and genotype on carcass traits and cellular development of the m. longissimus of cattle. Journal of Animal Science, Champaign, v.6, n.6, p.1597-1603,1978. 